\title{
The effects of movement on retrieval of emotional memory: an experiment on embodied cognition
}

\author{
Hassan Sabourimoghadam ${ }^{1}$, Mohammad Ali Nazari², Ali Jahan ${ }^{3}$, Saied Sabaghypour ${ }^{4}$ \\ 1-Associate Professor, Department of Cognitive Neuroscience, University of Tabriz, Tabriz, Iran. \\ 2- Associate Professor, Department of Cognitive Neuroscience, University of Tabriz, Tabriz, Iran. \\ 3- Assistant Professor, Department of Speech Therapy, Tabriz University of Medical Sciences, Tabriz, Iran. \\ 4- PhD Student in Cognitive Neuroscience, Department of Cognitive Neuroscience, University of Tabriz, Tabriz, \\ Iran (Corresponding Author). $\quad$ E-mail: Sabaghipour_s@tabrizu.ac.ir
}

Received: 05/04/2020

Accepted: 01/07/2020

\begin{abstract}
Introduction: Several behavioral and neuropsychological studies have shown that many cognitive processes are influenced by spatial, motor, and physical characteristics. For example, the relations between emotional valence of stimuli (positive vs. negative) and spatial dimensions (up vs. down) have been approved by many experiments (e.g. happiness is up).

Aim: The aim of the present study was to investigate whether the movement of the head to the left or right of the space could affect retrieval of Persian words with positive and negative valence?

Method: The research method was experimental. For this purpose, 38 participants from the population of Psychology Students of the University of Isfahan were selected by the public call and convenience sampling for participation in the research. DMDX software was used to evaluate the effect of movement on emotional memory. The results were then analyzed by repeated measure design using SPSS 24 software.

Results: The results of the study indicated that the number of retrieved words with valence was more than neutral ones. In addition, the interaction of valence and head movement was significant $(\mathrm{P}<0.05)$.

Conclusion: In addition to reviewing embodied accounts we finally conclude that abstract concepts such as positive and negative emotions might be under the influence of movement to the left or right of the space.
\end{abstract}

Keywords: Head movements, Emotions, Memory, Cognition

How to cite this article : Sabourimoghadam H, Nazari MA, Jahan A, Sabaghypour S. The effects of movement on retrieval of emotional memory: an experiment on embodied cognition. Shenakht Journal of Psychology and Psychiatry. 2020; 7 (3): 50-61 .URL: http://shenakht.muk.ac.ir/article-1-862-en.pdf

Copyright (C) 2018 the Author (s). Published by Kurdistan University of Medical Sciences. This is an open access article distributed under the terms of the Creative Commons Attribution-Non Commercial License 4.0 (CCBY-NC), where it is permissible to download, share, remix, transform, and buildup the work provided it is properly cited. The work cannot be used commercially without permission from the journal. 


\title{
بررسى تأثير حر كت در بازيابى حافظه هيجانى: مطالعهاى تجربى در باب شناخت بدفمند
}

\author{
حسن صبورى مقدم'، محمدعلى نظرى"، على جهان"، سعيد صباغى يور \\ ا. ا. دانشيار، گروه علوم اعصاب شناختى، دانشخاه تبريز، تبريز، ايران.

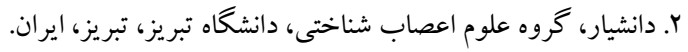

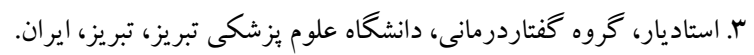

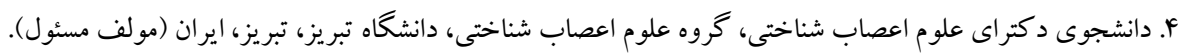

ايميل:Sabaghipour_s@ @abrizu.ac.ir

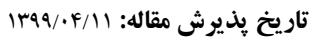

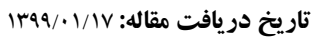

\section{جكيده}

مقدمه: مطالعات رفتارى و شواهد عصبشناختى نشان دادهاند بسيارى از بردازش هاى شناختى تحت تأثير ويز گىهاى فضايى، حر كتى

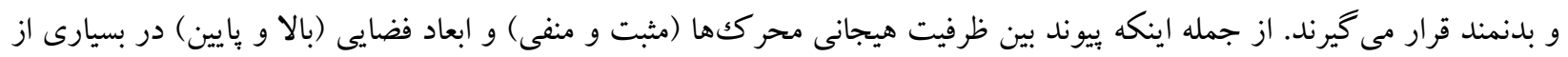
يزوهش ها تائيد شده است (مثل خوشحالى در موقعيت مكانى بالا). هدف: هدف از اجر ايى اين مطالعه اين بود كه آيا حركت سر به سمت راست يا جֶٍ فضا مى تواند بر بازيابى كلمات فارسى با ظرفيت

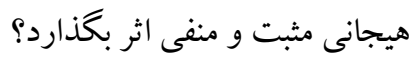

روش: روش يزوهش از نوع آزمايشى بود. به همين منظور با فراخوان عمومى شركت در يثزهش و به صورت نمونه گيرى در دسترس

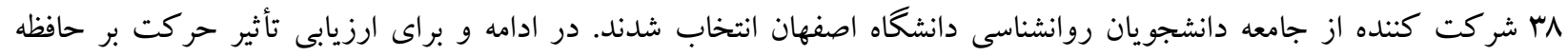
هيجانى از نرم افزار DMDX استفاده شد. سبس نتايج بهدست آمده با استفاده از نرم افزار SPSS نسخه اندازه گيرىهاى مكرر تحليل شد.

يافته ها: نتايج نشان داد تعداد كلمات بازيابى شده داراى بار هيجانى از كلمات خنثى بيشتر بوده و همجنين اثر تعاملى ظرفيت هيجانى كلمه و حر كت سر معنى دار شد (ه) (P<•).

نتيجه كيرى: ضمن مرورى بر روايتهاى شناخت بدنمند نتيجه گرفته شد كه مفاهيم انتزاعى از جمله هيجانهاى مثبت و منفى

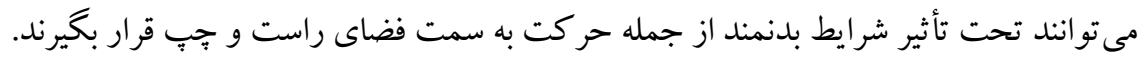
كليدوازهها: حركت سر، هيجانها، حافظه، شناخت 


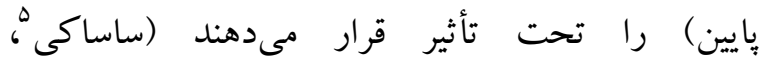
مقلدمه

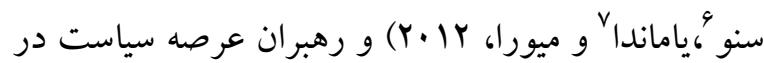
استفاده از كلمات با بار مثبت بيشتر از دست راست خود

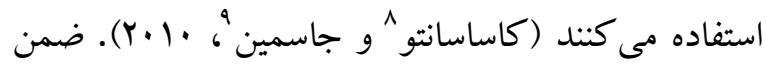
اينكه، فعاليتهاى حركتى بدنمند نقشى كاركردى در فر آيندهاى شناختى ايفا مى كنند (نيدنتال"، بارسالو"

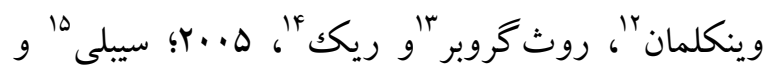

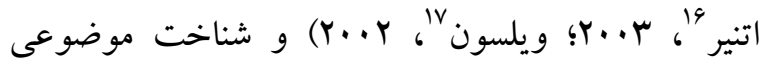
است كه تحت تأثير تجربههاى حسى-حر كتى و تعامل با

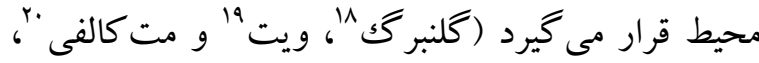

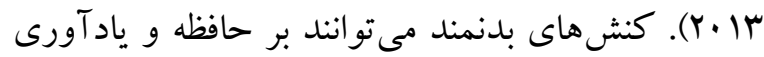
خاطرات افراد اثر خذار باشند. براى نمونه، در مطالعهاى

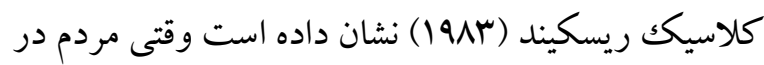
حال لبخند زدن يا در وضعيت صاف و نشسته هستند خاطرات مثبت كذشته را راحتتر يادآورى مى كنند و ور برعكس با اخم و يا تصور بلدنى خميده خاطرات منفى بيشترى به ذهنشان راه مىيابند. اين نوع اثرات در مورد مطابقت بين كنشهاى حركتى و ظرفيت هيجانى حامى اين فرضيهاند كه گويى حافظه هيجانى تحت تأثير

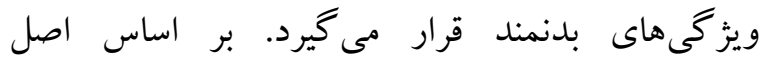

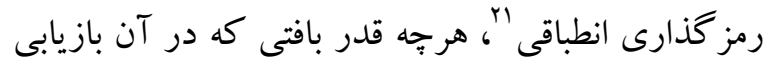

5- Sasaki

6-Seno

7. Yamada

${ }^{8}$ - Casasanto

9 - Jasmin

${ }^{10}$ - Niedenthal

${ }^{11}$ - Barsalou

12. Winkielman

${ }^{13}$-Krauth-Gruber

${ }^{14}$ - Ric

${ }^{15}$ - Sibley

${ }^{16}$ - Etnier

17 - Wilson

${ }^{18}$ - Glenberg

19. Witt

${ }^{20}$ - Metcalfe

${ }^{21}$ - Encoding specificity principle

1. Lakoff \& Johnson

${ }^{2}$ - Tey

3- Valence

4- Holmes \& Lourenco

براساس روايتهاى شناخت بدنمند در عصب يُزوهى امروز، كاركردهاى شناختى از ويزگى ها و تجارب فيزيكى بدن تأثير مى يذيرند. جورج ليكاف و جانسون در

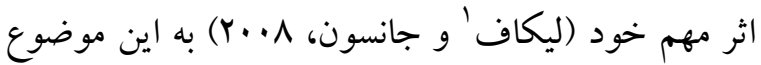
اشاره مى كنند كه وقتى مردم درباره ايدههاى مثبت و منفى سخن مى گويند معمولاً از استعارههاى فضايى بهره مى گيرند. از جمله اينكه كلمات با بار مثبت عاطفى با فضاى بالا و كلمات با بار منفى با فضاى پيايين بيوند

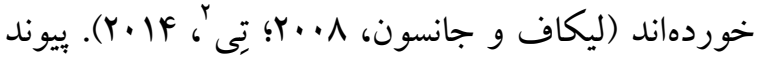
بين ظرفيت هيجانى بّو فضا در سنتهاى ديرين فرهنكى نيز يافت مىشود. از جمله اينكه بر اساس روايات بهصورت استحبابى توصيه شده است كه ورود به مكانهاى آلوده با پِاى جֶٍ و ورود به مسجد با پِى راست صورت بحيرند. بر اساس برخى روايات هم رقيب و عتيد، دو فرشته نويسنده اعمال انسان هستند كه رقيب بر

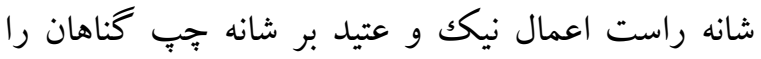
مىنويسند. از طرف ديخر در زبان فارسى (و انگليسى) از كلمه (راست) (كه به معنى موقعيت فضايى راست نيز هست) براى درست بودن سخن كسى استفاده مى كنيم. افزون بر اين، مطالعات تجربى امروز نشان دادهاند كه بيوندى هيجانى بين حالات شناختى جهره و فضا وجود دارد بهطورى كه در مقايسه با جهرههاى منفى، جهرههايى با بار هيجانى مثبت در سمت راست سريعتر بازشناسى

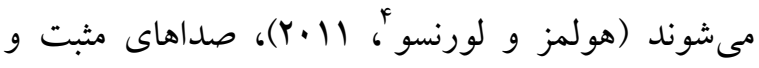
منفى، ادراكك محر ككها در موقعيتهاى عمودى (بالا و 
است. براى بررسى اين موضوع رابطه بين كنش حركتى

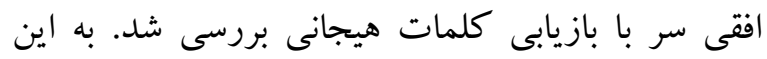
ترتيب كه از شركت كندكان خواسته شد فهرستى از بـاني كلمات مثبت، منفى و خنثى را به خاطر بسيارند. در مرحله بازيابى از آنها خواسته شد تا سر خود را بهصورت تصادفى به سمت راست و جٍِ حر كت دهند. با توجه به

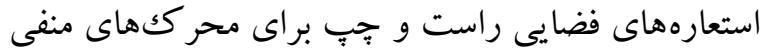
و مثبت (راست گويى كه كلمه (راست) رادر خود دارد) و نيز وجود اين موضوع در سنت فرهنگى و دينى ايرانيان (فرشته هاى رقيب و عتيد و توصيههاى دينى مبنى بر انجام اعمال خوب با اندامهاى راست)، فرض مطالعه اين بود كه با حركت سر به سمت راست بيشتر كلماتى كه داراى بار مثبت هستند بازيابى مىشوند و با حركت سر به سمت جִֶٍ كلماتى كه داراى بار منفى هستند بيشتر بازيابى خو اهند شد.

\section{روش}

مطالعه حاضر از نوع آزمايشى و جامعه مورد مطالعه شامل كليه دانشجويان مؤنث رشته روانشناسى دانشگاه اصفهان بود كه ^ץ نفر از آنها به روش نمونه گيرى در دسترس و

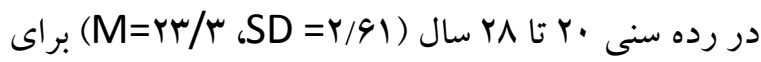
شركت در مطالعه انتخاب شدند. معيارهاى ورود به يثزوهش شامل راستدست بودن، عدم ابتلا به بيمارىهاى نورولوزيكك، بينايى طبيعى، عدم مصرف داروهاى مؤثر بر سيستم عصبى و عدم ابتلا به اختلالات حر كتى به ويزه

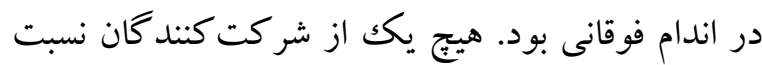
به هدف آزمايش اطلاعى نداشتند. دو نفر از

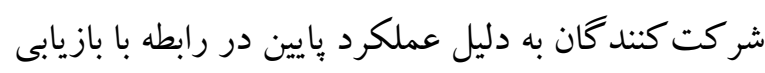
كلمات از تحليل نهايیى حذف شدند.
صورت مى گيرد با بافتى كه رمز گذارى در آن شكل كرفته هميوشانى بيشترى داشته باشند، بازيابى بيشتر تسهيل

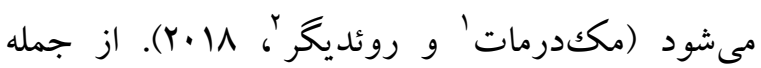
اينكه اگر فردى موقعيت بدنى مشابه با زمان تجربه يك رويداد را حين بازيابى آن تقليد كند، بازيابى حافظه

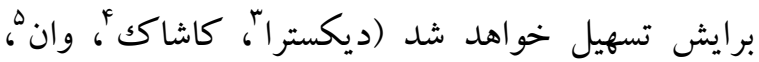

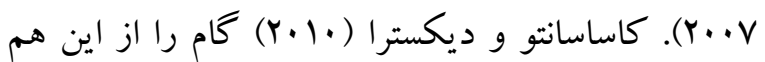

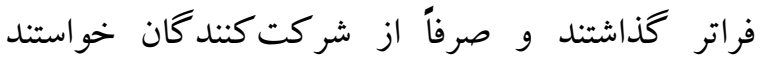
حركت هاى بدنى به سمت بالا و وِايين انجام دهند و

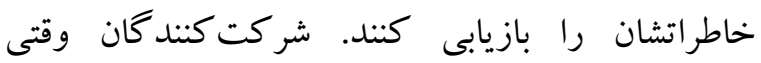

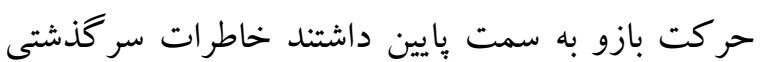
منفى را سريعتر بازيابى مى كردند. اثر مذكور براى خاطرات مثبت و حركت بازو به سمت بالا نيز مشاهده شد (كاساسانتو و ديكسترا، •(Y.1). كاساسانتو و بروين (Y.19) در مطالعه اخير خود نشان دادهاند كه اين موضوع در مرحله رمزگردانى حافظه نيز صدق مى كند و و كنشهاى حركتى يادگيرى كلمات ساده را تحت تأثير قرار مى دهد. درمجموع گويى هيجانها نه تنها از طريق كنشهاى حر كتى ابر از مىشوند بلكه كنشهاى حر كتى مى توانند بر رمز گردانى و بازيابى محر ككهاى هيجانى داراى بار مثبت و منفى نيز اثر كذار باشند. با توجه به مطالعاتى كه مختصراً در اينجا مرور شدند، هدف از مطالعه حاضر بررسى بازنمايى محر ككهاى هيجانى مثبت و منفى در فضاهاى به ترتيب راست و جِّ و تعيين نقش اين بازنمايى در بازيابى كلمات فارسى با ظرفيت مثبت، منفى و خنثى بوده

\footnotetext{
1- McDermott

2 - Roediger

3 - Dijkstra

${ }^{4}$ - Kaschak

5. Zwaan
} 
انجام دهند بهطورى كه هر حر كت سر سه ثانيه و با نظمى مشخص صورت بكيرد. به اين ترتيب كه قبل از اجراى آزمايش اصلى قادر باشند بهصورتى تصادفى و با سرعتى

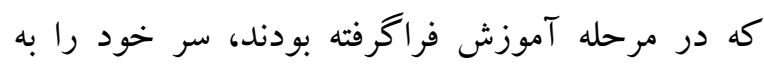

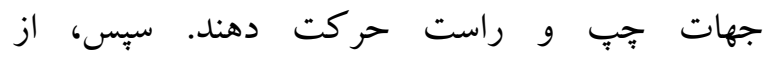
شركت كنند كان خواسته شد كه كلمات را به خاطر بسيارند (مرحله رمز گردانى). مشابه تكليف توبياس لوئجر

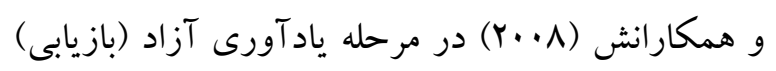

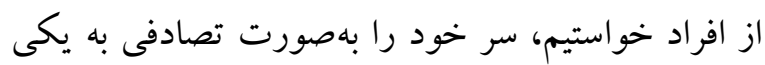

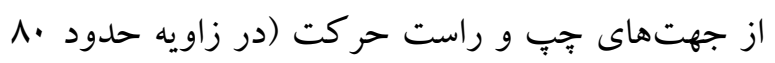
درجه) دهند و با هر بار انجام اين كار كلمهاى از ليست ارائهده را بازيابى كنند (شكل ()). آزمايشگر حين يادآورى كلمات مداخلهاى در اجراى تكليف نداشت. جهت حركت تصادفى سر (راست يا جِّ) و و كلمات كفته شده شركت كننده توسط آزمايشخر به ترتيب روى كاغذ ثبت شدند.
تحليل آمارى مطالعه معطوف به تعداد كلمات بازيابى شده بود. فرض اصلى مطالعه اين بود كه وقتى جهت حركت سر و ظرفيت هيجانى (مثل راست، مثبت) كلمات باهم همخوانى داشته باشند عملكرد بازيابى حافظه بهتر از حالت ناهمخو ان (مثل راست، منفى) است. براى انجام اين تحليل از روش واريانس در اندازهيرىهاى مكرر توسط نرمافزار SPSS نسخه YF استفاده شد. نومافزار Dmdx: كلمات انتخابى از هنجار هيجانى كلمات فارسى به صورتى تصادفى توسط نرمافزار Dmdx

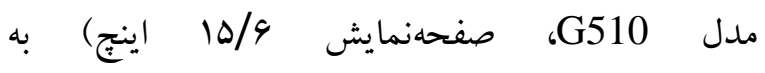
شركت كنند گان ارائه شدند. هر كلمه به مدت ها ثانيه ارائه شد و فاصله بين محرككها نيز ه/ • ثانيه بود. در

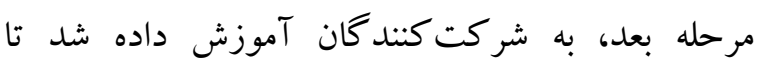
حركت افقى سر را با سرعتى متناسب (سه ثانيه يككبار با شنيدن صداى مترونوم نصبشده روى گوشى موبايل)
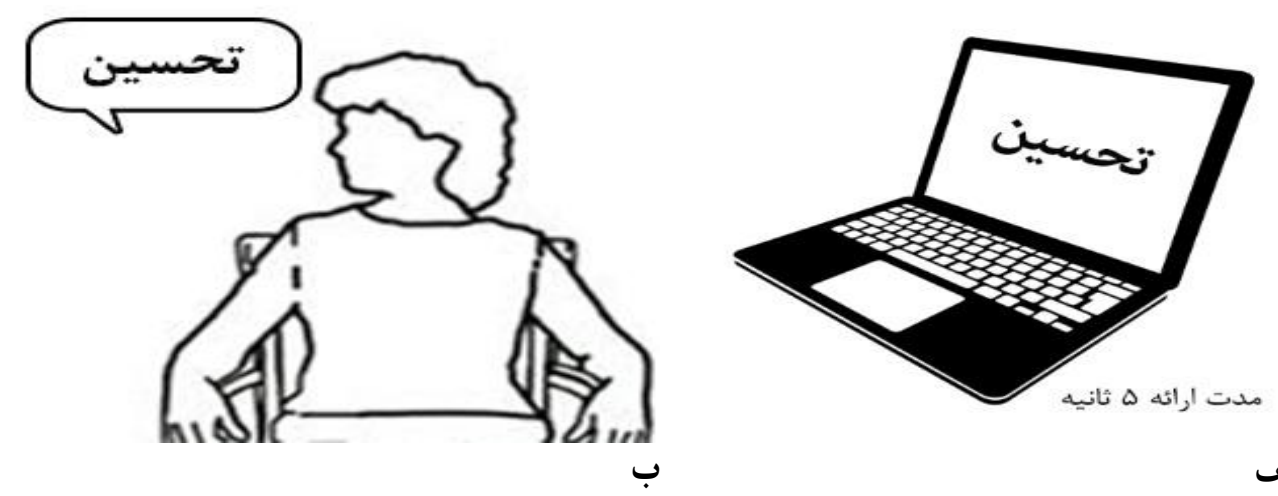

شكل 1 مراحل رمز كردانى و بازيابى تكليف.

الف

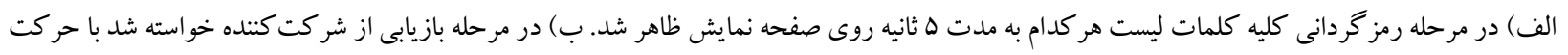
تصادفى سر به سمت راست و جِب كلمات را بازيابى كند. 
شر كت كننده در مطالعه برابر با س/Mr و انحر اف معيار نيز

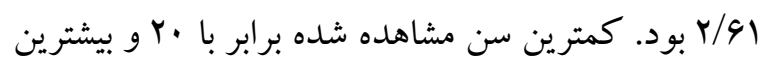
سن YM سال بود. تحليل آمارى مطالعه معطوف به كلمات بازيابى شده بود. مطابق با نتايج مطالعات قبلى اين انتظار وجود داشت كه شركت كنند كان در شرايط همخوان (مثل وازه مثبت، حر كت سر به سمت راست) در مقايسه با شرايط ناهمخوان (مثل وازه منفى، حركت سر به سمت راست) عملكرد بهترى در فر آيند بازيابى كلمات داشته باشند. در روند تحليل از روش واريانس اندازه گيرىهاى مكرر استفاده شد. كليه مقادير ه•/p معنادار در نظر كرفته شدند. نتايج اين تحليل نشان داد از ميان ·ـ كلمه

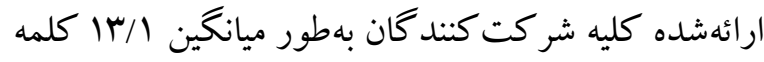
را بازيابى كردند. بهطور ميانگين تعداد كلمات مثبت

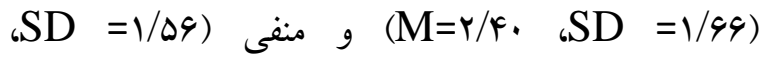
يادآورى شده در مقايسه با تعداد كلمات

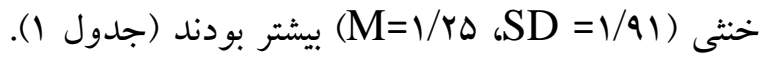
اين موضوع نشان مىدهد كلمات داراى بار هيجانى بهتر بهخاطرسيرده مىشوند و بازيابى آنها در مقايسه با كلمات خنثى سادهتر صورت مى گيرد.
تكليف شركت كنند كان رمز گذارى و بازيابى فهرستى از كلمات بود. بهاين ترتيب كه .ب كلمه شامل •ا كلمه داراى ظرفيت مثبت (انگيختخى > كلمه با ظرفيت منفى (انگيختخى >

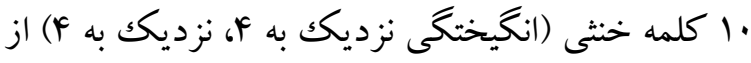
فهرست هنجارشده بارهيجانى كلمات فارسى (رجوع كنيد به نظرى و همكاران، rar|) انتخاب شدند. در مطالعه مذكور كلمات داراى خوشايندى و انخيختخى خنى تلقى شدهاند (مثل اجاق). كلمات خنثى بهمنظور جلو گيرى از كشف فرضيه توسط شركت كنند گان و بررسى وجود اثر واقعى جهت حركت سر در تكليف كنجانده شدند. از نظر طول كلمه، كلمات انتخابشده مثبت (SD = ت تفاوت معنادارى با يكديخر نداشتند (M94/r

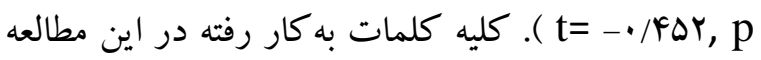
در ضميمه ا آمدهاند.

\section{يافتهها} تعداد كل افراد مورد مطالعه ^\ نفر از دانشجويان دختر رشته روانشناسى بود كه دو نفر از آنها به دليل عملكرد بايين از نتايج نهايى حذف شدند. ميانگين سن افراد

\begin{tabular}{|c|c|c|}
\hline انحر اف معيار & ميانغين & بار هيجانى \\
\hline $1 / 94$ & $r / f$ & كلمات مثبت \\
\hline $1 / 09$ & $r / r r$ & كلمات منفى \\
\hline $1 / 91$ & $1 / r \Delta$ & كلمات خنثى \\
\hline
\end{tabular}

(راست، جֶٍ) بهعنوان عوامل درون فردى و ميانگين تعداد كلمات بازيابى شده بهعنوان متغير وابسته در نظر
در تحليل آمارى با روش واريانس در اندازهيرىهاى مكرر ظرفيت هيجانى كلمه (مثبت، منفى) و حركت سر 


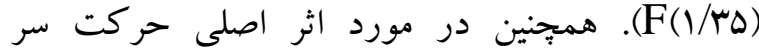

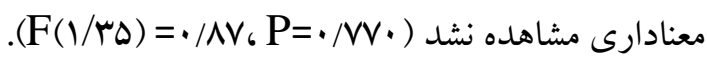

كرفته شدند. بر اساس آزمون گرينهاوس گیسر و با توجه به نتايج مندرج در جدول r اثر اصلى ظرفيت هيجانى كلمات به تنهايى معنادار نبود (PYF) ، P

جدول r تحليل واريانس در اندازهزيرىهاى مكرر براى كلمات بازيابىشده

\begin{tabular}{|c|c|c|c|c|c|}
\hline سطح معنىدارى & f آماره & ميانكين مجذذورات & درجه آزادى & مجموع مجذورات & عامل \\
\hline \multirow[t]{2}{*}{. / MFF } & $\cdot / 9 Y 1$ & $1 / \cdots$ & 1 & $1 / \cdots$ & بارهيجانى \\
\hline & & $1 / \cdot 19$ & ro & $r / / \ldots$ & خطا \\
\hline \multirow[t]{2}{*}{$\cdot / W$} & $\cdot / \cdot \wedge \mathrm{V}$ & $\cdot / 111$ & 1 & $\cdot / 111$ & حركت سر \\
\hline & & I/TAY & ro & $F F / M Q$ & خطا \\
\hline \multirow[t]{2}{*}{$\cdot / \cdots$} & $\mathrm{rV} / \cdot \mathrm{V} \cdot$ & $1 . r / r q 1$ & 1 & $1 . r / 491$ & حر كت سرX بار هيجانى مثبت و منفى \\
\hline & & $r / \Lambda 1 \Lambda$ & ro & $1 \pi T / 9 \pi q$ & خطا \\
\hline
\end{tabular}

در حين حركت به سمت راست بهطور ميانگين تعداد ب/ r

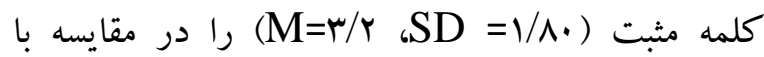
حركت به سمت جِّ با تعداد ميانگين ه/ ا كلمه مثبت

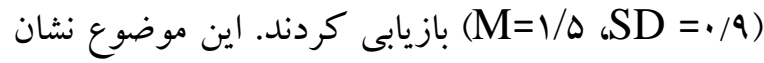

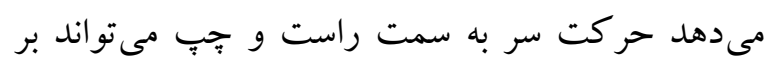
بازيابى بار هيجانى همخوان با حركت تأثير گذار باشد.

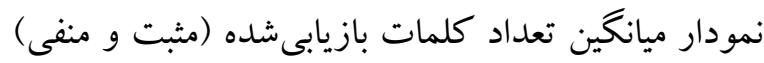
درحر كتهاى جֶٍ و راست سر در شكل r قابلمشاهده
همراستا با فرضيه اصلى مطالعه، اثر تعاملى ظرفيت هيجانى كلمه و حركت سر معنادار بود ( (-.

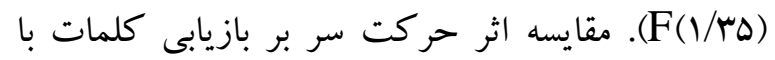
ظرفيت هيجانى مثبت و منفى تفاوت معنادارى را بين حركت به سمت راست و جِّ سر نشان داد بهطورى كه

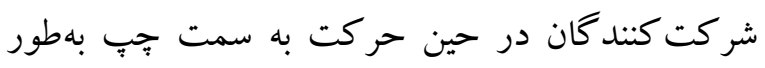

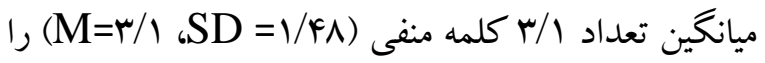
در مقايسه با حركت به سمت راست و ميانگين س/ كلمه منفى (.9//

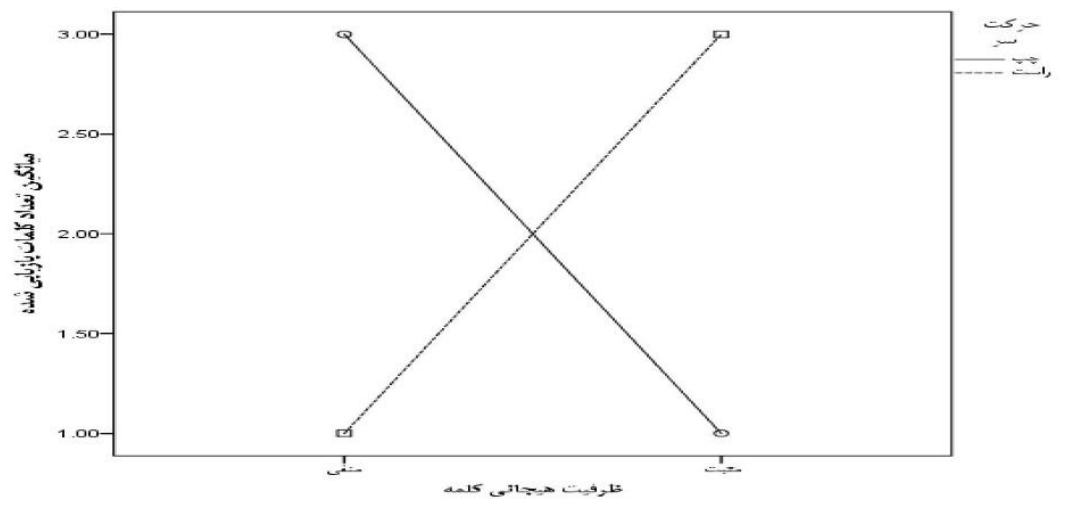

شكل r ميانكين تعداد كلمات بازيابع شده با ظرفيت مثبت و منفى در حر كت سر به سمت جِ و راست 


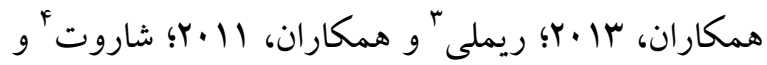

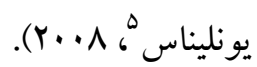

هدف از انجام مطالعه حاضر بررسى تأثير حركت افقى

نتايج همجنين نشان داد اثر تعاملى ظرفيت هيجانى كلمه و حركت سر معنادار است. افزون بر شواهد تجربى مبنى بر رابطه بين موقعيت فضايى عمودى (بالا و بايين) و ظرفيت هيجانى (مثبت و منفى)، در مطالعات مختلف ييوند قدرتمندى هم بين ظرفيت هيجانى و فضاى افقى (راست

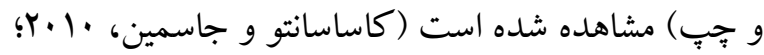

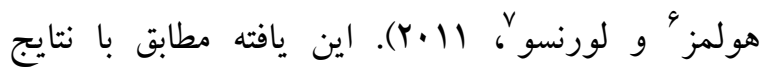

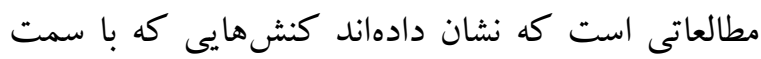
راست بدن انجام مىشوند، مثل انقباض ماهيجه دست راست يا سمت راست صورت، با هيجانهاى مثبت همبستگى دارند در حالى كه همين كنشها در سمت

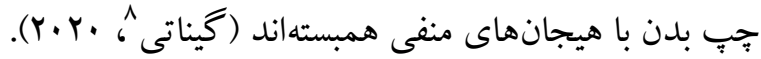
.Y.Y. حافظه هيجانى نيز در جندين مطالعه بررسى شده است

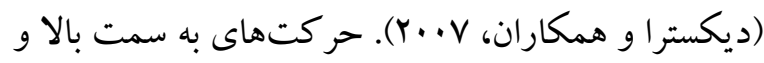
پايين بر ظرفيت هيجانى خاطرات بازيابى شده افراد

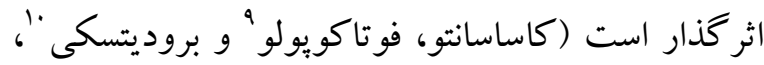

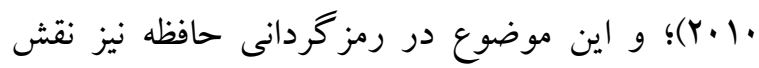

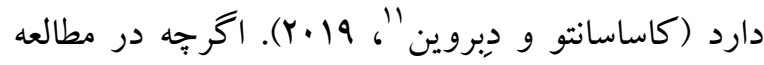
جارى حر كتهاى مربوطه از نوع ارتباطى نبودند مىتوان

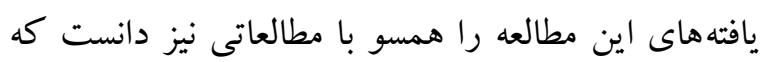

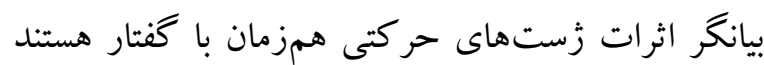

${ }^{3}$ - Rimmele

4- Sharot

5 - Yonelinas

${ }^{6}$ - Holmes

7 - Lourenco

${ }^{8}$ - Gainotti

9- Fotakopoulou

${ }^{10}$ - Boroditsky

${ }^{11}$ - De Bruin

1- Cattaneo
2- Gomez 
مىتوان يافتهاى اين نوع مطالعات را توضيح داد؛ بنابراين، به نظر مىرسد هم ويثز گیىهاى بدنمند و هم ويزگ گیىاى زبانى در وييوند هيجان و فضا نقش داشته باشند، ليكن هنوز سهم نسبى اين دو مشخص نشده است. يكى ديخر از راههاى تبيين نتايج اين مطالعه و مطالعات

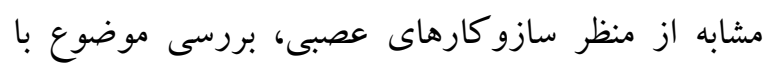
روايت كلاسيك ديويدسون در جانبى شدن هيجانهاى

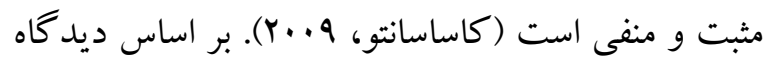
ديويدسون درباره جانبىشدن رفتارهاى نزديكى و و اجتناب، رفتارهاى نزديك شدن به اشياء در نيمكره جِّب و رفتارهاى اجتناب از اشياء در نيمكره راست به ويزه در نواحى بيشانى جانبى شدهاند (ديويدسون، اكمانها

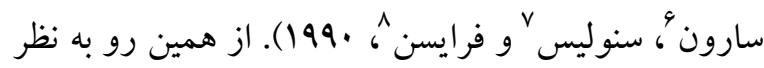
نظر مىرسد هيجانهاى مثبت و رفتارهاى نزديكك شدن

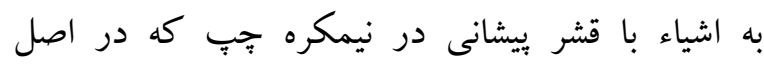
كنترل كننده دست راست است باهم ارتباط دارند. توضيح

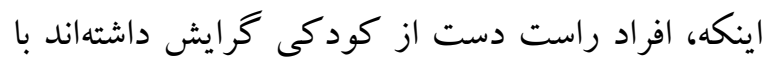
دست غالب خود به اشيايى كه مثبت قلمداد مى كردهاند نزديك شوند. اين مسئله مىتواند ارتباط بين هيجانهاى مثبت و رفتارهايى نزديكى با دست غالب كه تحت كنترل نيمكره مقابل است را تا اندازهاى تبيين كند.

\section{نتيجه كيرى}

در اين مطالعه نشان داده شد ويز گیى انضمامى حركت در فضا با حافظه انتزاعى هيجان از منظر كاركردى رابطه دارند. اين مسئله با استعارههاى مورد استفاده در زبان

5- Ekman

6- Saron

7- Senulis

${ }^{8}$ - Friesen

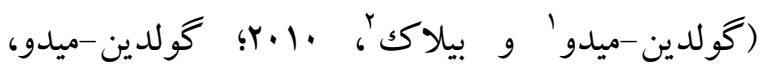
.$(Y \cdot)$. بيوند مشابه (راست) با ظرفيت (امثبت) و ("جٍِ)" با ظرفيت

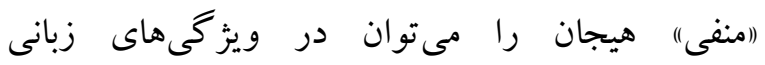
فرهنگ هاى مختلف نيز مشاهده كرد. اصطلاحاتى مثل (حرف راست) و ("مرد راست كردار)،، ظرفيت هيجانى مثبت را با فضاى راست بيوند مىزنند و در مقابل در توصيهاى اسلامى مثل اينكه (ابا پِاى جٍِ وارد مكانهاى آلوده شويد) جِيزى منفى با فضاى جِب مر تبط شده است.

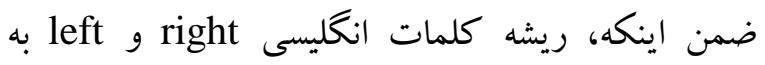
sinister و dexter- ترتيب به معنى (ماهر)" و (شيطانى) است. جنين الكوى مشابهى در فرهنگكاى ديخر هم

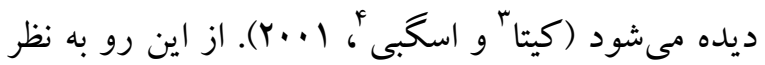

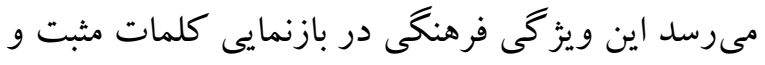
منفى نقشى ناخود آكاه ايفا كرده باشد. در رابطه با تبيين دادههاى اين نوع مطالعات بايد دو نوع تفسير را در نظر گرفت: تفسير شناخت بلنمند و

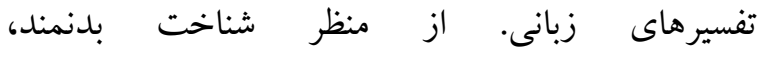
شركت كنند گان از آنجا كلمات مثبت را با سمت راست ييوند مىزنند كه بيوندى حسى -حر كتى با ظرفيتهاى

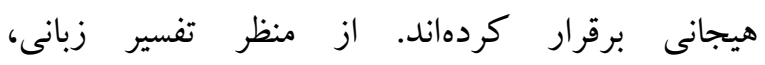

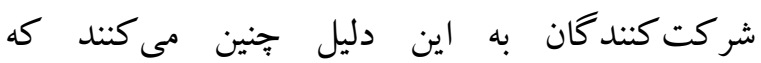
ويز كى هاى زبانى جنين بيوندى را برقرار كرده است (مثل

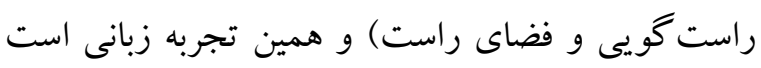
كه اين رابطه را در شبكه مفهومى شكل داده است. در حال حاضر گويى با استفاده از هر دوى اين روايتها

\footnotetext{
1- Goldin-Meadow

2- Beilock

3 - Kita

4- Essegbey
} 
نويسندكان مقاله بدينوسيله از تمامى كسانى كه در اجراى اين بزوهش همكارى داشتهاند بهويزه سر كار خانم زهرا مساح كه در اجراى تكليف مشاركت داشتند و همجنين دانشجويان روانشناسى دانشگاه اصفهان كمال

$$
\text { تشكر و قدردانى را دارند. }
$$

\section{References}

Casasanto, D. (2009). Embodiment of abstract concepts: good and bad in right-and lefthanders. Joumal of Experimental Psychology: General, 138(3), 351 .

Casasanto D, \& De Bruin A. (2019). Metaphors we learn by: Directed motor action improves word learning. Cognition, 182, 177-183.

Casasanto D, \& Dijkstra K. (2010). Motor action and emotional memory. Cognition, 115(1), 179185.

Casasanto D, \& Jasmin K. (2010). Good and bad in the hands of politicians: Spontaneous gestures during positive and negative speech. PloS one, 5(7), el1805.

Cattaneo Z, Lega C, Boehringer J, Gallucci M, Girelli L, \& Carbon CC. (2014). Happiness takes you right: The effect of emotional stimuli on line bisection. Cognition \& emotion, 28(2), 325344.

Davidson RJ. (1992). Anterior cerebral asymmetry and the nature of emotion. Brain Cogn, 20(1), 125151.

Davidson RJ, Ekman P, Saron CD, Senulis JA, \& Friesen WV. (1990). Approach-withdrawal and cerebral asymmetry: emotional expression and brain physiology: I. Joumal of personality and social psychology, 58(2), 330.

Dijkstra K, Kaschak MP, \& Zwaan RA. (2007). Body posture facilitates retrieval of autobiographical memories. Cognition, 102(1), 139-149.

Forster KI, \& Forster JC. (2003). DMDX: A Windows display program with millisecond accuracy. Behavior Research Methods, Instruments, \& Computers, 35(1), 116-124.
فارسى همخوانى دارد. شر كت كنند گان اين مطالعه حين حر كت به سمت راست كلمات مثبت بيشترى را نسبت به كلمات منفى بازيابى كردند. همجينين شر كت كنند گان در

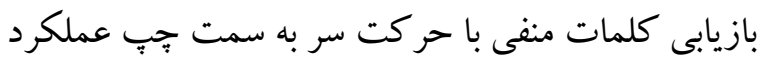

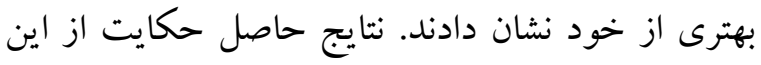
دارد كه حركت در فضا مى تواند با اطلاعات هيجانى و بازيابى اين اطلاعات از حافظه ارتباط داشته باشد. از محدوديتهاى اصلى مطالعه حاضر اين بود كه افراد جֶٍ دست در آن شركت نداشتند؛ بنابر اين مقايسه بازيابى هيجانى افراد راست دست با اين گروه نيز مىتواند

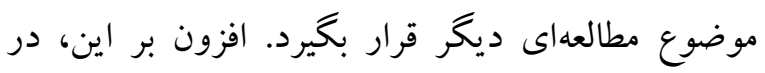
اينجا ويز گىهاى كلمات از جمله بسامد هر كلمه در زبان فارسى، ميزان انتزاعى يا انضمامى بودن كلمات و قابليت تصور بالا يا بايين آنها نيز مورد بررسى قرار نخرفته

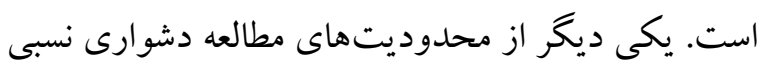
تكليف بازيابى كلمات و درنتيجه تعداد كلمات بازيابى شده بايين بود؛ بنابراين بهتر است در مطالعات آتى سطوح دشوارى مختلف در زمينه بازيابى كلمات نيز بررسى شود. مسئله ديخر اينكه در اينجا صرفاً در مرحله بازيابى حافظه دئه دستكارىهاى حركتى انجام شدند و از اين رو بررسى

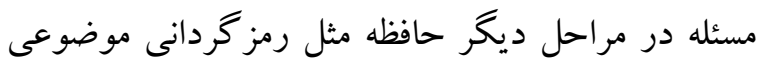
است كه مىتوان در مطالعهاى ديخر به آن برداخت. بهعلاوه، حركتهاى انتخابى در آزمايش اين مطالعه

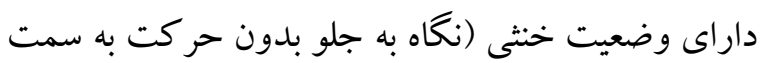
جֶٍ يا راست) نبودند. در مجموع بررسى اين اثر با اندازه نمونه بزرگكتر مىتواند نقش ويز كىهاى حسى -حر كتى را در مراحل مختلف حافظه بيشتر برملا كند. سياسگز ارى 
Gainotti G. (2020). The History of Research on Emotional Laterality. In Emotions and the Right Side of the Brain (pp. 27-52): Springer.

Glenberg AM, Witt JK, \& Metcalfe J. (2013). From the revolution to embodiment: 25 years of cognitive psychology. Perspectives on psychological science, 8(5), 573-585.

Goldin Meadow S. (2010). When gesture does and does not promote leaming. Language and cognition, 2(1), 1-19.

Goldin Meadow S, \& Beilock SL. (2010). Action's influence on thought: The case of gesture. Perspectives on psychological science, 5(6), 664674.

Gomes CF, Brainerd CJ, \& Stein LM. (2013). Effects of emotional valence and arousal on recollective and nonrecollective recall. Journal of Experimental Psychology: Leaming, Memory, and Cognition, 39(3), 663.

Holmes KJ, \& Lourenco SF. (2011). Common spatial organization of number and emotional expression: A mental magnitude line. Brain Cogn, 77(2), 315-323.

Kita S, \& Essegbey J. (2001). Pointing left in Ghana: How a taboo on the use of the left hand influences gestural practice. Gesture, 1(1), 7395.

Lakoff G, \& Johnson M. (1999). Philosophy in the Flesh (Vol. 4): New york: Basic books.

Lakoff G, \& Johnson M. (2008). Metaphors we live by: University of Chicago press.

Loetscher T, Schwarz U, Schubiger M, \& Bugger P. (2008). Head tums bias the brain's internal random generator. Current Biology, 18(2), R60-R62.

McDermott KB, \& Roediger HL. (2018). Memory (encoding, storage, retrieval). General Psychology FA2018. Noba Project: Milwaukie, OR, 117-153.
Natale M, Gur RE, \& Gur RC. (1983). Hemispheric asymmetries in processing emotional expressions. Neuropsychologia, 21(5), 555565.

Nazari MA, Khayati F, Poursharifi H, Hakimi M, \& Shojaei Z (2014). Primary Normalization of Emotional Farsi Words. Applied Psychological Research Quarterly, 4(4), 41-71. doi:10.22059/japr.2014.52578.

Niedenthal PM, Barsalou LW, Winkielman P, Krauth Gruber S, \& Ric F. (2005). Embodiment in attitudes, social perception, and emotion. Personality and social psychology review, 9(3), 184-211.

Rimmele U, Davachi L, Petrov R, Dougal S, \& Phelps EA. (2011). Emotion enhances the subjective feeling of remembering, despite lower accuracy for contextual details. Emotion, 11(3), 553.

Riskind JH. (1983). Nonverbal expressions and the accessibility of life experience memories: A congruence hypothesis. Social Cognition, 2(1), 62-86.

Sasaki K, Seno T, Yamada Y, \& Miura K. (2012). Emotional sounds influence vertical vection. Perception, 41(7), 875-877.

Sharot T, Yonelinas AP. (2008). Differential timedependent effects of emotion on recollective experience and memory for contextual information. Cognition, 106(1), 538-547.

Sibley BA, Etnier JL. (2003). The relationship between physical activity and cognition in children: a meta-analysis. Pediatric exercise science, 15. 256_243,(3).

Tay D. (2014). Lakoff and the theory of conceptual metaphor. The Bloomsbury companion to cognitive linguistics, 49-59.

Wilson M. (2002). Six views of embodied cognition. Psychonomic bulletin \& review, 9(4), 625-63. 


\begin{tabular}{|c|c|c|}
\hline منفى & خنثى & مثبت \\
\hline شيطان & آسفالت & آغوش \\
\hline اعدام & آگهى & آفتاب \\
\hline بمب & آهن & ازدواج \\
\hline تخريب & اجاق & اميد \\
\hline تومور & بشقاب & بجه \\
\hline جسد & بِارجه & بوسه \\
\hline جنايت & يوتين & ييشرفت \\
\hline جهنم & تخته & ييروز \\
\hline حادثه & جلسه & تحسين \\
\hline خيانت & دستگاه & تولد \\
\hline
\end{tabular}

